\title{
Prevalence and Associated Factors of Hypertension among Nepalese Civil Servants
}

\author{
Mahendra G1,2, Sanjana Z², Ariful BC², Shaikh AS², Ahsan GU2 and \\ Mohammad Delwer $\mathrm{HH}^{2 *}$ \\ ${ }^{1}$ Ministry of Health and Population, District Health Office Dhulikhel, Kavre, Nepal \\ ${ }^{2}$ North South University Dhaka, Bangladesh
}

Research Article

Volume 2 Issue 5

Received Date: August 27, 2018

Published Date: October 10, 2018

DOI: $10.23880 /$ mjccs-16000179

*Corresponding author: Mohammad Delwer Hossain Hawlader, Assistant Professor, Department of Public Health, North South University, Plot \# 15, Block \# B, Bashundhara R/A, Dhaka, Bangladesh, Email: mohammad.hawlader@northsouth.e $\mathrm{du}$

\section{Abstract}

Background: Hypertension is one of the major global emerging health problems in this industrial world. Prevalence of is increasing daily. Overall awareness and modifying one's lifestyle could be beneficial to the reduction of hypertension. Majority of the hypertension cases are found in the developing countries. South Asian countries such as India, Bangladesh and Nepal have a higher risk of hypertension which is rapidly increasing.

Methods: Analytical cross-sectional study was conducted to determine the prevalence and associated factors of hypertension among civil servants in a Nepalese federal state. Structured questionnaire was used and face to face interview were carried out by the researcher himself. Blood Pressure (BP) was measured and hypertension was categorized, height and weight was measurements to attain the Body Mass Index (BMI). The participants were exclusively selected $247(F=68, M=179)$ civil servants who are working in Nepalese federal state number 5. Chi-square test has been carried out for comparing proportions in categorical variables. Logistic regression has been used to find out the adjusted odds ratio. All difference has been considered statistically significant at the $\mathrm{p}<0.05$ level.

Results: Study found 27.9\% prevalence of hypertension (F= 8.8 \%, M = 35.2\%) with statistically significance with alcohol consumption $(p=0.024)$, known diabetes $(p=0.026)$. According to the logistic regression model result of the study, physical activity $(p=0.218)$ and its intensity $(p=0.368)$ with hypertension is not statistically significant. Similarly smoking also has not statistical significance with hypertension $(p=0.121)$. Study shows amount of salt intake in a day $(<5 \mathrm{gm}=13.8 \%,>5-<10$ gm. $=51.4 \%$ and $>10 \mathrm{gm} .=34.8 \%)$ that is higher amount than World Health Organization (WHO) recommendation $(<5 \mathrm{gm}$.). 


\section{Medical Journal of Clinical Trials \& Case Studies}

Conclusion: Prevalence of hypertension is higher among civil servant than ordinary people. Alcohol consumption, diabetes mellitus and age has significant association with hypertension among Nepalese civil servant.

Keywords: Prevalence; Obesity; Hypertension; Civil-servant; BP; BMI

Abbreviations: BP: Blood Pressure; BMI: Body Mass Index; HTN: Norm Tension and Hypertension; WHO: World Health Organization; NCDs: Non-Communicable Diseases; SPSS: Statistical Package for the Social Sciences; NHRC: Nepal Health Research Council; CVD: Cardio Vascular Disease; MET: Metabolic Equivalent.

\section{Introduction}

Blood pressure (BP) can be defined as pressure of blood against in the inner arterial wall. Hypertension is defined an increase in systolic blood pressure $>140 \mathrm{~mm}$ of $\mathrm{Hg}$ and diastolic blood pressure $>90 \mathrm{~mm}$ of $\mathrm{Hg}$. Sir George Puckering first formulated the concept that blood pressure in a population is distributed continuously as a 'bell shaped curve' with no real separation between norm tension and hypertension (HTN) [1]. An estimate made by the World Health Organization (WHO) for 2025 is that 1.56 billion adults will likely have HTN [2]. According to recent estimates from the World Health Organization, two-thirds of hypertensive people live in developing countries. Africa has the highest prevalence of HTN (29.6\%) followed by the Eastern Mediterranean (26.9\%), South East Asia (24.7\%), Europe (23.3\%), the Western Pacific (18.7\%), and America (18.2\%). Among South Asian countries, Nepal reported the second highest proportion of hypertensive people (27.3\%) after Afghanistan (29\%) [3].

Nepal is one of the least developed countries, now trend of HTN prevalence is in increasing every year. WHO estimate deaths related to Non-Communicable Diseases (NCDs) in Nepal have increased from $51 \%$ in 2010 to $60 \%$ in 2014 [4]. Federal Democratic Republic of Nepal has more than thirty ministries and every ministry expanded their network from central level to local level. Civil servants are the liable people of government to implement the policy into action. More often than not, that key responsible person shows a higher prevalence of NCDs than the general public [5]. Literature found that lack of physical activity, use of alcohol and tobacco consumption, lack of fruits and vegetable consumption, negligence on regular health check-up, lack of satisfaction on job are the risk factors of obesity and HTN among the Nepalese population [5]. Prevalence of obesity has found to be higher in households those have a secure income and job security. Having a stable and good income allows for an easier access to various foods consumption, but majority of these people do not engage in any physical activity. Due to this reason, Cardio Vascular Disease such as HTN is highly prevalent among these people.

The prevalence of HTN also varies among the lifestyles of each person as well as their job duties. People who work in different field have different characteristics. Most of the civil servants do not engage in any physical activity during their leisure time [5]. The lack of physical activity is highly correlated to a higher risk of obesity and other NCDs. Civil servants are associated as one of the most influential person in the society, as they are the role models that possess the power and the influence over a community. With that said, Prevalence of obesity and HTN are increasing day by day among this group. Previous studies shows those who are in a senior position, married, and physical lifestyle rapidly increased the risk of visceral obesity and HTN [5]. This study was conducted upon the civil servants in Nepal to find out the prevalence and associated risk factor according to their behaviour and lifestyle patterns.

\section{Methods}

This was an analytical cross-sectional study, included all male and female civil servants working as administrative staff under different ministries of government of Nepal. An exclusive inclusion and exclusion criteria has made to select the respondents. A convenience sampling technique was applied to selected respondents. Nepal constructed its new constitution from elected constitutional assembly and applied this newly constructed constitution since Sept 20, 2015, replacing the Interim Constitution of 2007. According to the new constitution Nepal is divided into different federal states (State 1, State 2, State 3, State 4, State 5, State 6 and State 7) [6]. This study has conducted in Federal State Number 5 , one of the 7 federal states of Federal Democratic 


\section{Medical Journal of Clinical Trials \& Case Studies}

Republic of Nepal, located in western part. The area of Federal State number 5 is $22,288 \mathrm{~km}^{2}$ and population $4,891,028$ and the topography of this province includes all part of ecological area like Terai, Pahad and Himal. This province has thirteen districts [7].

To assess the fruits and vegetables consumption; question was asked to the respondent with following threshold; $125 \mathrm{ml}$ (half cup) cooked or chopped vegetables and 80grams (edible part of one whole medium size fruit like banana, apple or equivalent) consumption in a day $[4,8]$. Salt intake was measured by asking the questions on amount of salt consumed in a day and WHO recommendation of salt intake $5 \mathrm{gm}$. (1 Tea Spoon) in a day will be taken as a threshold for the measurement. For the measurement of physical activity, questions were asked to the respondent whether respondent accumulate physical activities $<150$ minutes or $<500$ Metabolic Equivalent (MET) in a week will be considered as sedentary lifestyle and similarly intensity of the activity. Walking, slow cycling, was considered as moderate intensity and fast walking, running, swimming, jogging was considered as vigorous intensity $[9,10]$.

\section{Ethical Considerations}

Ethical approval for this study was obtained from North South University, Dhaka, Bangladesh. In addition, informed written consent was obtained from each and every respondent before the data collection. Permission was taken from the authority of the District Administrative Office of the respective districts. Privacy and confidentiality were strictly maintained and participants had rights to refuse or withdraw from the study at any time.

\section{Data Analysis}

Statistical Package for the Social Sciences (SPSS) version 21.0 was used to analyse the data. Appropriate statistics such as mean, median and standard deviation has been used. Chi-square test has been carried out for comparing proportions in categorical variables. Logistic regression was used to find out adjusted odds ratio. All difference has considered statistically significant at $p$ $<0.05$ level.

\section{Results}

A total of 247 civil servants were recruited in this analytical cross sectional study. Different independent variables have been measured to find-out outcome. Table 1 shows the frequency of socio-demographic variables of the study population. Study found $18.6 \%$ of respondents were aged between 19 to 29 years, likewise $24.3 \%$ of respondents were 30 to 40 years, $30.4 \%$ of respondents were 41 to 51 years and $26.7 \%$ of respondents were 52 to 60 years of age. Majority of the participants $(72.5 \%)$ were male and only $27.5 \%$ were female. Regarding their designation, majority of the respondent (54.7\%) belongs to assistant level staff, $25.9 \%$ were support staff, $15.0 \%$ were class III officer, $3.2 \%$ were class II officer and only $1.2 \%$ were class I officer. Table also shown the education, where $47 \%$ respondents had intermediate level of education, $34 \%$ had graduate level and $19 \%$ postgraduate level of education. Most of the respondents $(85.0 \%)$ were married, some of them (14.2\%) were never married and only few $(0.8 \%)$ were divorced. In terms of religion; $94.3 \%$ respondents were Hindu, $4 \%$ respondents were Buddhist and only few were Muslim (1.2\%) and Christian (0.4\%). Most of respondents (41.7) had their monthly income between 20,000 to 30,000 Nepali Rupees (NPR) per month, $21.5 \%$ had 30,000 to $40,000 \mathrm{NPR}, 15.8 \%$ had 40,000 to 50,000 thousands and $21.1 \%$ had 50,000 and above. Majority (62.3\%) of the respondents were living in urban area, $20.6 \%$ were living in semi-urban area, $14.6 \%$ were in rural area and only $2.4 \%$ were living in urban slum area.

\begin{tabular}{|c|c|c|c|}
\hline \multicolumn{2}{|l|}{ Variable } & Frequency (n) & Percentage (\%) \\
\hline \multirow{3}{*}{ Age } & $19-29$ Years & 46 & 18.6 \\
\cline { 2 - 4 } & $30-40$ Years & 60 & 24.3 \\
\cline { 2 - 4 } & $41-51$ Years & 75 & 30.4 \\
\cline { 2 - 4 } & $52-60$ Years & 66 & 26.7 \\
\cline { 2 - 4 } & & 179 & 72.5 \\
\hline \multirow{2}{*}{ Gender } & Male & 68 & 27.5 \\
\cline { 2 - 4 } & Female & & \\
\hline
\end{tabular}

Mohammad Delwer HH, et al. Prevalence and Associated Factors of Hypertension among Nepalese Civil Servants. Med J Clin Trials Case Stud 


\section{Medical Journal of Clinical Trials \& Case Studies}

\begin{tabular}{|c|c|c|c|}
\hline \multirow{5}{*}{ Designation } & Supportive Staff & 64 & 25.9 \\
\hline & Assistant Level & 135 & 54.7 \\
\hline & Class III Officer & 37 & 15.0 \\
\hline & Class II Officer & 8 & 3.2 \\
\hline & Class I Officer & 3 & 1.2 \\
\hline \multirow{3}{*}{ Education } & Intermediate Level & 116 & 47.0 \\
\hline & Graduation Level & 84 & 34.0 \\
\hline & Post-Graduation Level & 47 & 19.0 \\
\hline \multirow{3}{*}{ Marital status } & Never Married & 35 & 14.2 \\
\hline & Married & 210 & 85.0 \\
\hline & Separated or Divorced & 2 & 0.8 \\
\hline \multirow{4}{*}{ Religion } & Hindu & 233 & 94.3 \\
\hline & Buddhist & 10 & 4.0 \\
\hline & Christian & 1 & 0.4 \\
\hline & Muslim & 3 & 1.2 \\
\hline \multirow{4}{*}{ Monthly family income } & 20 to 30 Thousands Rupees & 103 & 41.7 \\
\hline & 30 to 40 Thousands Rupees & 53 & 21.5 \\
\hline & 40 to 50 Thousands Rupees & 39 & 15.8 \\
\hline & 50 Thousands Rupees and above & 52 & 21.1 \\
\hline \multirow{4}{*}{ Residential area } & Urban Area & 154 & 62.3 \\
\hline & Urban Slum Area & 6 & 2.4 \\
\hline & Semi Urban Area & 51 & 20.6 \\
\hline & Rural Area & 36 & 14.6 \\
\hline
\end{tabular}

Table 1: Basic characteristics of the study participants.

Table 2 shows the frequency of clinical variables of the study. Among total 247 respondents, $27.9 \%$ had hypertension and 72.1 respondents were free from hypertension. Table also shows $9.3 \%$ were known diabetes mellitus, only $0.8 \%$ respondent had known renal disease, $1.2 \%$ of the respondents used hormonal methods of contraceptives as majority (72.5\%) of the study participants are male.

\begin{tabular}{|c|c|c|c|}
\hline \multicolumn{1}{|c|}{ Variables } & Frequency (n) & Percentage (\%) \\
\hline \multirow{2}{*}{ Hypertension } & Yes & 69 & 27.9 \\
\cline { 2 - 4 } & No & 178 & 72.1 \\
\hline \multirow{2}{*}{ Known diabetes } & Yes & 23 & 9.3 \\
\cline { 2 - 4 } & No & 224 & 90.7 \\
\hline \multirow{2}{*}{ Known renal disease } & Yes & 2 & 0.8 \\
\cline { 2 - 4 } Known rheumatoid disease & No & 245 & 2.0 \\
\hline \multirow{2}{*}{ Use of hormonal contraceptives. } & Yes & 5 & 98.0 \\
\cline { 2 - 4 } & No & 242 & 1.2 \\
\cline { 2 - 4 } & Yes & 67 & 27.1 \\
\cline { 2 - 4 } & Not applicable & 177 & 71.7 \\
\hline
\end{tabular}

Table 2: Frequency table of clinical Variables.

Table 3 shows that majority (47.0\%) of the respondent had normal weight, $35.6 \%$ were overweight, $13.8 \%$ Class I obese, $2.8 \%$ class II obese however Class III obese and below normal weight were very minor that, both were only $0.4 \%$. Table also shows the frequency regarding intensity of physical activities of the 


\section{Medical Journal of Clinical Trials \& Case Studies}

respondents, where $5.3 \%$ respondents do not do any physical activities during week however $61.1 \%$ of respondents do moderate physical activities like slow walking, slow cycling, and $33.6 \%$ respondents do vigorous physical activates like fast walking, jogging, running. It was also found that $33.6 \%$ respondents have habit of alcohol drink, $11.3 \%$ were ex-smoker of the respondents. However, only $3.6 \%$ respondents were current smoker. According to this table, only $0.8 \%$ respondent do not consume vegetable every day, however
$26.3 \%$ of respondents consumed less than $1 / 2$ cup ( $125 \mathrm{ml})$ cooked or chopped vegetable in a day, $72.9 \%$ respondent consumed $1 / 2$ cup $(125 \mathrm{ml})$ cooked or chopped vegetable in a day. $36 \%$ of the respondents do not consume fruit daily, however $39.7 \%$ of respondents consume less than edible part of one whole medium size fruit or two small fruit/80 gm. and $24.3 \%$ of the respondents consume edible part of one whole medium size fruit or two small fruit/80gm or more in a day.

\begin{tabular}{|c|c|c|c|}
\hline \multicolumn{2}{|r|}{ Variables } & Frequency (n) & Percentage (\%) \\
\hline \multirow{6}{*}{ BMI } & BMI<= 18.5: Below normal weight & 1 & 0.4 \\
\hline & BMI $>=18.5$ and $<25$ : Normal weight & 116 & 47 \\
\hline & BMI $>=25$ and $<30:$ Overweight & 88 & 35.6 \\
\hline & BMI $>=30$ and $<35$ : Class I Obesity & 34 & 13.8 \\
\hline & BMI $>=35$ and $<40$ : Class II Obesity & 7 & 2.8 \\
\hline & BMI >= 40: Class III Obesity & 1 & 0.4 \\
\hline \multirow{3}{*}{$\begin{array}{l}\text { Intensity of physical } \\
\text { activities }\end{array}$} & \begin{tabular}{|c|} 
No Physical Activities \\
\end{tabular} & 13 & 5.3 \\
\hline & $\begin{array}{c}\text { Moderate Physical Activities like slow walking, } \\
\text { slow cycling }\end{array}$ & 151 & 61.1 \\
\hline & Vigorous Physical activities like fast walking. & 83 & 33.6 \\
\hline \multirow{2}{*}{$\begin{array}{c}\text { Duration of physical } \\
\text { activities }\end{array}$} & Less than 150 cumulative minutes. & 83 & 33.6 \\
\hline & 150 minutes or more cumulative minutes. & 164 & 66.4 \\
\hline \multirow{2}{*}{ Habit of alcohol drink } & Yes & 83 & 33.6 \\
\hline & No & 164 & 66.4 \\
\hline \multirow{2}{*}{ Ex - smoker } & Yes & 28 & 11.3 \\
\hline & No & 219 & 88.7 \\
\hline \multirow{2}{*}{ Habit of smoking } & Yes & 9 & 3.6 \\
\hline & No & 238 & 96.4 \\
\hline \multirow{2}{*}{ Habit of tobacco use } & Yes & 50 & 20.2 \\
\hline & No & 197 & 79.8 \\
\hline \multirow{3}{*}{$\begin{array}{l}\text { Amount of vegetable } \\
\text { consumption }\end{array}$} & No vegetable consumed daily & 2 & 0.8 \\
\hline & $\begin{array}{l}\text { Less than } 1 / 2 \text { cup } /(125 \mathrm{ml}) \text { cooked or chopped } \\
\text { in a day }\end{array}$ & 65 & 26.3 \\
\hline & $\begin{array}{c}1 / 2 \mathrm{cup} /(125 \mathrm{ml}) \text { or more cooked or chopped } \\
\text { in a day }\end{array}$ & 180 & 72.9 \\
\hline \multirow{3}{*}{$\begin{array}{l}\text { Amount of fruits } \\
\text { consumption }\end{array}$} & \begin{tabular}{|l|} 
No fruit consumed daily \\
\end{tabular} & 89 & 36 \\
\hline & $\begin{array}{l}\text { Less than edible part of one whole medium size } \\
\text { fruit or two small fruit/80 gm }\end{array}$ & 98 & 39.7 \\
\hline & $\begin{array}{l}\text { Edible part of one whole medium size fruit or } \\
\text { two small fruit/80 gm or more }\end{array}$ & 60 & 24.3 \\
\hline \multirow{3}{*}{ Amount of salt intake } & $<5$ gm/ 1 tea spoon. & 34 & 13.8 \\
\hline & $5-10 \mathrm{gm} / 1-2$ tea spoon. & 127 & 51.4 \\
\hline & $>10 \mathrm{gm} / 2$ tea spoon. & 86 & 34.8 \\
\hline Satisfaction scale on job & Dissatisfied & 3 & 1.2 \\
\hline
\end{tabular}

Mohammad Delwer HH, et al. Prevalence and Associated Factors of Hypertension among Nepalese Civil Servants. Med J Clin Trials Case Stud 


\begin{tabular}{|c|c|c|c|}
\hline & Some satisfied & 157 & 63.6 \\
\cline { 2 - 4 } & Strongly satisfied. & 87 & 35.2 \\
\hline \multirow{4}{*}{ Means of transport used } & On foot & 129 & 52.2 \\
\cline { 2 - 4 } & $\begin{array}{c}\text { By private vehicle (Car/Motorcycle/Scooter } \\
\text { etc.) }\end{array}$ & 71 & 28.7 \\
\cline { 2 - 4 } Time of health check-up & By public transportation. & 47 & 19 \\
\cline { 2 - 4 } & Never & 80 & 32.4 \\
\cline { 2 - 4 } & Once in a year & 98 & 18.2 \\
\cline { 2 - 4 } & $\begin{array}{c}\text { 3 times in a year or more. (At least 4 months } \\
\text { interval or less.) }\end{array}$ & 24 & 9.7 \\
\hline
\end{tabular}

Table 3: Frequency table of predisposing variables.

Table 4 shows that gender is strongly associated with hypertension $(p=<0.01)$. It has been also found that alcohol consumption is statistically significant with hypertension $(p=0.02)$. Study also found that who have been suffering from diabetes mellitus also significantly associated with hypertension ( $p=0.03)$. Other factors such as marital status, smoking, previous habit of smoking, duration of physical activity and means of transport were not statistically significant.

\begin{tabular}{|c|c|c|c|c|}
\hline & $>150$ cumulative minutes & 61 & 117 & \multirow{3}{*}{$p$-value } \\
\hline \multirow{2}{*}{\multicolumn{2}{|c|}{ Variables }} & \multicolumn{2}{|c|}{ Hypertension } & \\
\hline & & Yes & No & \\
\hline \multirow{2}{*}{ Gender } & Male & 63 & 116 & \multirow{2}{*}{$<0.01$} \\
\hline & Female & 6 & 62 & \\
\hline \multirow{2}{*}{ Marital status } & Never married & 5 & 30 & \multirow{2}{*}{0.09} \\
\hline & Married & 64 & 146 & \\
\hline \multirow{2}{*}{$\begin{array}{l}\text { Habit of alcohol } \\
\text { consumption }\end{array}$} & Yes & 31 & 52 & \multirow{2}{*}{0.02} \\
\hline & No & 38 & 126 & \\
\hline \multirow[t]{2}{*}{ Habit of smoking } & Yes & 5 & 9 & 0.12 \\
\hline & No & 64 & 174 & \\
\hline \multirow{3}{*}{$\begin{array}{c}\text { Means of transport used to } \\
\text { go to the office. }\end{array}$} & On foot & 34 & 95 & \multirow{3}{*}{0.37} \\
\hline & By private vehicle & 18 & 53 & \\
\hline & By public transport & 17 & 30 & \\
\hline \multirow{2}{*}{ Known diabetes mellitus } & Yes & 11 & 12 & \multirow{2}{*}{0.02} \\
\hline & No & 58 & 166 & \\
\hline \multirow{2}{*}{ Ex-smokers } & Yes & 10 & 18 & \multirow{2}{*}{0.33} \\
\hline & No & 59 & 160 & \\
\hline $\begin{array}{c}\text { Duration of physical } \\
\text { activities }\end{array}$ & $<150$ cumulative minutes & 22 & 47 & 0.72 \\
\hline
\end{tabular}

Table 4: Association between socio-economic and hypertension related variables.

Table 5 presents the results of univariate and multivariate logistic regression analysis. In univariate analysis, it shows that male gender is more prone to develop hypertension (OR $=5.61,95 \% \mathrm{CI}=2.29-13.69)$. After adjustment byage, Body Mass Index (BMI), level of education, marital status, religion, monthly family income and residential area in multivariate analysis, the association still remain significant. Similarly, habit of alcohol consumption found to be statistically significant $(\mathrm{OR}=1.97,95 \% \mathrm{CI}=1.11-3.51)$ but after adjustment by same variables, it becomes marginally insignificant (OR = $1.76,95 \% \mathrm{CI}=0.95-3.26$ ). Also known diabetes mellitus has to be found significantly associated with hypertension $(\mathrm{OR}=2.62,95 \% \mathrm{CI}=1.10-6.27)$. After adjustment in 


\section{Medical Journal of Clinical Trials \& Case Studies}

multivariate logistic regression model, the association still $\quad$ remain same $(\mathrm{OR}=2.59,95 \% \mathrm{CI}=1.02-6.55)$.

\begin{tabular}{|c|c|c|c|c|}
\hline \multirow{2}{*}{ Characteristics } & \multicolumn{2}{|c|}{ Univariate model } & \multicolumn{2}{c|}{ Multivariate model } \\
\cline { 2 - 5 } & Unadjusted odds ratio & $\mathbf{9 5 \%} \mathbf{~ I ~}$ & Adjusted odds ratio & $\mathbf{9 5 \%}$ CI \\
\hline Gender & 5.61 & $2.29-13.69$ & ${ }^{*} 4.44$ & $1.66-11.88$ \\
\hline Habit of alcohol consumption & 1.97 & $1.11-3.51$ & ${ }^{*} 1.76$ & $0.95-3.26$ \\
\hline Diabetes Mellitus & 2.62 & $1.10-6.27$ & 2.59 & $1.02-6.55$ \\
\hline
\end{tabular}

*Adjustment was done by age, BMI, level of education, marital status, religion, monthly family income and residential area. Table 5: Univariate and multivariate logistic regression analysis to confirm the association of hypertension and related variables

\section{Discussion}

This analytical cross-sectional study was designed with the justification regarding prevalence of hypertension and its associated factors among Nepalese civil servants. This study has used different types of variables; these are socio-demographic, clinical and predisposing factors. In this study 247 subjects were enrolled (179 male and 68 female) among them most of the staffs were assistant level staff (54.7\%). In this study prevalence of HTN was $27.9 \%$, a very similar study on same topic in different study subjects (urban area of Kathmandu) has found a bit higher prevalence (32.5\%) [3]. Likewise, a study which conducted among aged over 50 years found that, the prevalence of HTN is $44.9 \%$ [11]. However, according to the Nepal Health Research Council (NHRC), the only national reliable government organization for authentic data has published $20 \%$ prevalence of HTN among ordinary population [1]. However result shows smoking habit, salt intake, means of transportation used were not statistically significant with HTN. Previous study shows that smoking is one of the powerful risk factor for Cardio Vascular Disease (CVD), somewhat surprisingly this study found that participants who have hypertension only few of them are smoker [12].

A study found that $55.40 \%$ of the hypertensive patients have sedentary type of lifestyle and among them most of was overweight [1]. Physical exercise is a key component of life style modification factor to reduce HTN. Numerous studies suggested that there is positive association to reduce both systolic and diastolic blood pressure [13]. Evidence based experimental study found that physical activity has favourable effect on blood pressure reduction that is with HTN [14]. Nevertheless this study found that there is no significant association between physical activities and the HTN. Likewise study result sows surprisingly BMI has no association with HTN though many of research showed that BMI is one of the major associated factor of CVDs.

Similarly, amount of salt intake was not significant with HTN in this study. However previous study shows intake of salt consumption in Nepali community is quite higher [15]. Accordingly, this study showed consumption of salt intake is higher in Nepali community according to WHO recommendation. Study report that 51.4\% respondent consume between 5-10 gm. salt per day, $34.8 \%$ consume more than $10 \mathrm{gm}$. per day and only $13.8 \%$ consume less than $5 \mathrm{gm}$. in a day.

Despite the well-recognized associated factor, alcohol consumption is statistically significant with $\operatorname{HTN}(p=0.02)$. Previous study also found that alcohol consumption had a statistically positive signification $(p=0.035)$ with HTN [3]. Likewise, the study found that respondent who has diabetes mellitus is strongly significant with HTN $(p=0.03)$. Diabetes mellitus is one of well recognized associated factor of the HTN. A community based cross sectional study found that one in every ten participants $(10.7 \%)$ had diabetes mellitus [3]. Likewise, this study also found almost similar result, $9.3 \%$ of respondents have known diabetes mellitus. This study also found association between gender and HTN $(p<0.01)$. Male participants were more prevalent than female participants.

According to the study only $24.3 \%$ participants consume recommended amount of fruit $(>80 \mathrm{gm})$ per day. Likewise consumption of vegetable is quite good, $72.9 \%$ consume recommended amount $(>=125 \mathrm{ml})$ per day. However study shows there are no significant between fruits and vegetable consumption with HTN. A study from 


\section{Medical Journal of Clinical Trials \& Case Studies}

national survey found that intake of fruits and vegetables consumption are insufficient than WHO recommendation, likewise it showed consumption in rural area is slightly in higher amount than urban area [4].

This study notify that there is no association between marital status and HTN $(p=0.9)$. In spite of similar study found there is a strong association between marital status and HTN $(p=<0.001)[16]$.

This study notices Prevalence of HTN is higher in civil servants of Nepal than ordinary population. Similarly, this study identifies some of major associated factors of HTN among Civil Servants of Nepal. A study showed one a third of all hypertensive were under treatment, likewise only $11.7 \%$ were under the control of blood pressure [17] These factors could be targeted to improvement the health status of this group to reduce mortality from NCDs. Consumption of alcohol is one of the example it is positive significant with hypertension. Similarly, consumption of alcohol is quite high in this group (33.6\%). Alcohol control mechanism should indorse to reduce the prevalence of NCDs. Implementation the mandatory physical exercise at office is recommended to reduce the NCDs among Civil Servant.

\section{Limitations of the study}

As this study has been conducted in a particular group, results of this study can't be generalized. Moreover, study could not use any biological samples.

\section{Conclusion}

Prevalence of HTN is increasing daily in lower middle income country like Nepal. This study was conducted with justification of prevalence and associated factors with hypertension. Study has justified most of associated variables with HTN. Study found that alcohol consumption and diabetes is major risk factor of hypertension. BCC regarding periodic health check-up, healthy habits and periodic screening program for the detection of diabetes is recommended to early detection which can control NCDs. Ministry of Public Administration has responsibility to manage the administrative staff in Nepal. On the other hand, amount of salt intake; means of transportation used to go to office were not statistical significance with HTN. This analytical cross-sectional study is the first ever study in Nepal among the government employee (civil servants) with the justification of prevalence and associated factors of hypertension. This study will be useful for policy makers, stakeholders and further scientific evidence based studies in the field of CVDs and obliviously NCDs.

\section{References}

1. Gautam A, Khan GA, Timilsina S (2017) Prevalence of Risk Factors of Hypertension in Nepalese Population. International Archives of BioMedical and Clinical Research 3(1): 44-46.

2. World Health Organization, Regional Office SouthEast Asia.

3. Dhungana RR, Pandey AR, Bista B, Joshi S, Devkota S (2016) Prevalence and Associated Factors of Hypertension: A Community-Based Cross-Sectional Study in Municipalities of Kathmandu, Nepal. Int J Hypertens 2016: 1656938.

4. Aryal KK, Mehata S, Neupane S, Abhinav Vaidya, Meghnath Dhimal, et al. (2015) The Burden and Determinants of Non Communicable Diseases Risk Factors in Nepal: Findings from a Nationwide STEPS Survey. Plos One 10(8): 1-49.

5. Simkhada P, Poobalan A, Simkhada PP, Amalraj R, Aucott L (2009) Knowledge, Attitude, and Prevalence of Overweight and Obesity among Civil Servants in Nepal. Asia Pac J Public Health 23(4): 507-517.

6. Nepalese Federal States.

7. Gwillim Law. Statoids.

8. Agudo A (2005) World Health Organization.

9. (2017) Sedentary Vs Active.

10. Nelson ME, RW Jea (2017) The Office of Disease Prevention and Health Promotion.

11. Manandhar K, Koju R, Sinha N (2013) Prevalence and Associated Risk Factors of Hypertension Among People Aged 50 years and more in Banepa Municipality, Nepal. Kathmandu Univ Med J 10(3): 35-36.

12. Virdis A, Giannarelli C, Neves MF, Taddei S, Ghiadoni L (2010) Cigarette Smoking and Hypertension. Curr Pharm Des 16(23): 2518-2525. 


\section{Medical Journal of Clinical Trials \& Case Studies}

13. Hegde SM, Solomon SD (2015) Influence of Physical Activity on Hypertension and Cardiac Structure and Function. Curr Hypertens Rep 17(10): 77.

14. Diaz KM, Shimbo D (2013) Physical Activity and the Prevention of Hypertension. Curr Hypertens Rep 15(6): 659-668.

15. Vaidya A, Pathak RP, Pandey MR (2012) Prevalence of hypertension in Nepalese community triples in 25 years: a repeat cross-sectional study in rural Kathmandu. Indian Heart J 64(2): 128-131.
16. Khanal MK, Dhungana RR, Bhandari P, Gurung $\mathrm{Y}$, Paudel KN (2017) Prevalence, associated factors, awareness, treatment, and control of hypertension: Findings from a cross sectional study conducted as a part of a community based intervention trial in Surkhet, Mid-western region of Nepal. Plos One 12(10): e0185806.

17. Karmacharya BM, Koju RP, Logerfo JP, Kwun Chuen Gary Chan, Ali H Mokdad, et al. (2017) Awareness, treatment and control of hypertension in Nepal: findings from the Dhulikhel Heart Study. Heart Asia 9(1): 1-8. 